\title{
Rapid resolution of acute subdural hematoma in child with severe head injury: a case report
}

\author{
Jae-Young Park', Kyung-Sub Moon ${ }^{1 *}$, Jung-Kil Lee ${ }^{2}$ and Kyung-Woon Jeung ${ }^{3}$
}

\begin{abstract}
Introduction: Rapid spontaneous resolution of traumatic acute subdural hematoma is an infrequent phenomenon and mainly develops in a case of simple acute subdural hematoma without parenchymal contusion. However, it has been rarely reported in a pediatric case with severe initial head injury.

Case presentation: A 7-year-old Asian girl with traumatic acute subdural hematoma was transferred to our hospital for an emergency operation based on the results of an initial computed tomography scan and neurological examination. However, a repeat computed tomography scan two hours after trauma disclosed considerable reduction of the hematoma and midline shift with neurological improvements. Serial follow-up imaging studies demonstrated apparent redistribution of the hematoma over the cerebellar tentorium, posterior interhemispheric fissure and subarachnoid space. The patient was discharged with mild confusion 40 days after the admission.
\end{abstract}

Conclusion: A follow-up computed tomography scan is strongly recommended before surgery when a child with a severe head injury presents with any sign of neurological improvement, especially with a mixed density hematoma on the initial computed tomography scan.

Keywords: Acute subdural hematoma, Pediatric head injury, Rapid resolution, Spontaneous resolution

\section{Introduction}

Traumatic acute subdural hematoma (ASDH) is a neurosurgical emergency with mortality as high as $60 \%$ to $80 \%$ [1]. Most of these patients undergo urgent hematoma evacuation via a craniotomy except for those with poor general condition or with irreversible brain damage. Several criteria have been used for the proper indication and timing of surgical evacuation for ASDH. In general, prompt surgical management of an ASDH with a thickness greater than $10 \mathrm{~mm}$ or midline shift greater than $5 \mathrm{~mm}$ on a computed tomography $(\mathrm{CT})$ scan could be tried regardless of the patient's Glasgow Coma Scale (GCS) score [2]. The clinical aspects are also important parameters for choosing the treatment options, in addition to the radiological criteria. Even in a comatose patient (GCS score less than nine) who has a hematoma that is less than $10 \mathrm{~mm}$ thick and a midline shift less than $5 \mathrm{~mm}$, surgical evacuation should be

\footnotetext{
* Correspondence: moonks@chonnam.ac.kr

'Department of Neurosurgery, Chonnam National University Hwasun

Hospital, Hwasun-gun, Jeollanamdo 519-763, South Korea

Full list of author information is available at the end of the article
}

performed if the patient's GCS score decreases by two or more points during the hospitalization, or the patient presents with asymmetric or fixed and dilated pupils and/or the intracranial pressure (ICP) exceeds $20 \mathrm{mmHg}$ [3]. Even in a case not indicated for emergency operation, careful monitoring of the neurological status is mandatory because of the possibility of unexpected worsening of the neurological status.

By contrast, spontaneous resolution of an ASDH that initially required an operation is an infrequent phenomenon and mainly develops in a case of simple ASDH without parenchymal contusion [4-12]. To the best of our knowledge, spontaneous resolution of an ASDH has been rarely reported in a pediatric case $[5,9,10]$, especially with a severe initial head injury. We present the clearly relevant images of such a case and discuss the mechanisms related to the rapid resolution of ASDH.

\section{Case presentation}

A 7-year-old Asian girl presented with deterioration of mental status to a nearby hospital after a pedestrian

\section{Biomed Central}


traffic accident (3:30 p.m.). The patient was comatose with a score of five on the GCS and had a left hemiparesis with a dilated right pupil. The CT scan, performed at 3:53 p.m., demonstrated a right frontotemporoparietal ASDH with severe midline shift (Figure 1a). The patient was transferred to our hospital for emergent surgery. A neurological examination revealed a score of 7T (eye=three, verbal=intubated, motor $=$ four) on GCS without motor deficits or pupillary abnormalities. A repeat CT scan at 5:46 p.m. disclosed considerable reduction of the hematoma and midline shift (Figure 1b). Based on the definitive improvements of neurological signs and CT findings, we decided to monitor the neurological status and check the follow-up CT scan, with conservative medical treatment. A follow-up CT scan six hours after the accident showed a further resolution of the ASDH with apparent redistribution over the cerebellar tentorium, posterior interhemispheric fissure and subarachnoid space (Figure 1c). Magnetic resonance imaging
(MRI), performed two weeks later, demonstrated a residual subacute subdural hematoma and multiple cerebral contusions (Figure 1d). The patient recovered consciousness on the tenth day and was discharged with mild confusion 40 days after the admission.

\section{Discussion}

Even though traumatic ASDH is a neurosurgical emergency requiring immediate therapeutic intervention, some reports have shown unexpected resolution of the hematoma within two hours after the initial injury, which prevented the need for emergency surgery $[4,6,8]$. Rapid spontaneous resolution generally develops in a case of simple ASDH without parenchymal contusion, after a minor head injury $[4,6]$.

Two possible mechanisms have been proposed for this infrequent phenomenon. First, the hematoma may be diluted by flow of cerebrospinal fluid (CSF) through the arachnoid tear, followed by retrograde flow into the
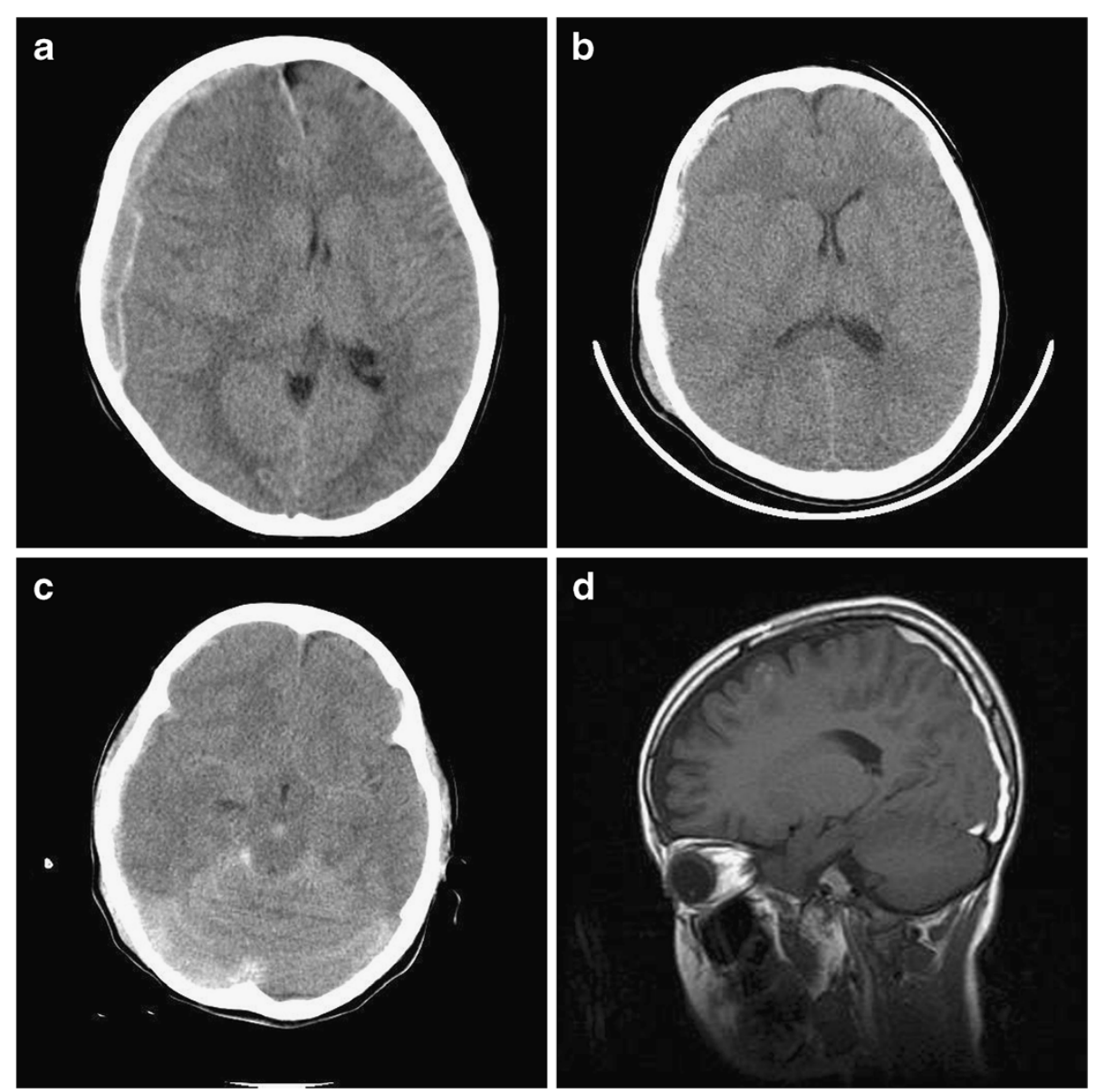

Figure 1 a: Initial computed tomography scan demonstrating mixed density of right hemispheric acute subdural hematoma with midline shift of more than $10 \mathrm{~mm}$. b: Computed tomography (CT) scan two hours after the accident showing marked reduction of the hematoma with more condensed density and improvement of the midline shift. c: CT scans six hours after the accident showing prominent subarachnoid hemorrhage and redistribution of the hematoma into the tentorial and interhemispheric subdural spaces. $\mathbf{d}$ : Sagittal $\mathrm{T}_{1}$-weighted magnetic resonance image, obtained two weeks after the accident, revealing a subacute-staged subdural hematoma with frontal contusion. 
subarachnoid space. This is supported by the presence of a low-density band between the ASDH and the inner table of the skull on CT scan [11]. Transient neurological deterioration with subsequent dramatic improvement may be related to CSF influx and efflux within the subdural space $[4,6,8,11]$. The prominent subarachnoid space with cerebral atrophy may facilitate dilution of ASDH [11]. Second, the compression and redistribution of the hematoma can be induced by cerebral swelling and increased ICP. This hypothesis is supported by the finding of dispersal of blood in the cerebellar tentorium or interhemispheric subdural space on the follow-up MRI $[8,11]$. In addition, the accompanying skull fracture and dural injury may allow the hematoma to drain into the subgaleal or intradiploic space [4]. Of interest, the reported cases of spontaneous resolution of ASDH generally occurred in aged patients. This reason can be explained by unique characteristics of the pediatric brain; there is no brain atrophy or excessive subarachnoid space to dilute or redistribute the hematoma.

In our case, marked hematoma reduction with condensed density and increased subarachnoid hemorrhage, on serial CT scans, can be explained by the dilution mechanism. Furthermore, the thickened tentorial and interhemispheric hematoma on follow-up imaging studies also support redistribution of the hematoma.

\section{Conclusion}

Our case suggests that both dilution and redistribution of a hematoma account for the infrequent phenomenon of spontaneous resolution of an ASDH. Even in a child with a severe head injury, when there is any sign of neurological improvement, especially with a mixed density hematoma on the initial CT scan, a follow-up CT scan is strongly recommended before surgery.

\section{Consent}

Written informed consent was obtained from the patient's legal guardian for publication of this manuscript and accompanying images. A copy of the written consent is available for review by the Editor-in-Chief of this journal.

\section{Competing interests}

The authors declare that they have no competing interests.

\section{Authors' contributions}

JYP wrote the manuscript. KSM performed the treatment and was the coordinator of the study. JKL summarized the patient notes and carried out the literature search. KWJ participated in the draft of the study, and in the conception of the study. All authors read and approved the final manuscript.

\section{Author details}

${ }^{1}$ Department of Neurosurgery, Chonnam National University Hwasun Hospital, Hwasun-gun, Jeollanamdo 519-763, South Korea. ${ }^{2}$ Department of Neurosurgery, Chonnam National University Hospital, Gwangju, South Korea. ${ }^{3}$ Department of Emergency Medicine, Chonnam National University Hwasun Hospital, Hwasun-gun, Jeollanamdo, South Korea.
Received: 17 September 2012 Accepted: 30 January 2013

Published: 14 March 2013

\section{References}

1. Matsuyama T, Shimomura T, Okumura Y, Sakaki T: Rapid resolution of symptomatic acute subdural hematoma: case report. Surg Neurol 1997, 48:193-196

2. Zacko JC, Harris L, Bullock MR: Surgical Management of Traumatic Brain Injury. In Youmans Neurological Surgery. Volume 4. 6th edition. Edited by Winn HR. Philadelphia: Saunders; 2011:3424-3452.

3. Bullock MR, Chesnut R, Ghajar J, Gordon D, Hartl R, Newell DW, Servadei F, Walters BC, Wilberger JE: Surgical management of acute subdural hematomas. Neurosurgery 2006, 58:16-24.

4. Berker M, Gulsen S, Ozcan OE: Ultra rapid spontaneous resolution of acute posttraumatic subdural hematomas in patient with temporal linear fracture. Acta Neurochir (Wien) 2003, 145:715-717.

5. Coşar M, Eser O, Aslan A, Ela Y: Rapid resolution of acute subdural hematoma and effects on the size of existent subdural hygroma: a case report. Turk Neurosurq 2007, 17(3):224-227.

6. Inamasu J, Nakamura Y, Saito R, Kuroshima Y, Mayanagi K, Ohba S, Ichikizaki K: Rapid resolution of traumatic acute subdural hematoma by redistribution. Am J Emerg Med 2002, 20:376-377.

7. Lee CH, Kang DH, Hwang SH, Park IS, Jung JM: Spontaneous rapid reduction of a large acute subdural hematoma. J Korean Med Sci 2009, 24:1224-1226.

8. Mirzai H, Yaldiz C, Eminoglu M, Orguc S: Ultra fast resolution of acute post-traumatic subdural haematoma. J Neurol Neurosurg Psychiatry 2005, 76:1738.

9. Nagao T, Aoki N, Mizutani H, Kitamura K: Acute subdural hematoma with rapid resolution in infancy: case report. Neurosurgery 1986, 19(3):465-467.

10. Suzuki Y, Kawamata T, Matsumoto H, Kunii N, Matsumoto K: A resolving sign of acute subdural hematoma: from report of two cases. No Shinkei Geka 1998, 26(11):1025-1029.

11. Tsui EY, Fai Ma K, Cheung YK, Chan JH, Yuen MK: Rapid spontaneous resolution and redistribution of acute subdural hematoma in a patient with chronic alcoholism: a case report. Eur J Radiol 2000, 36:53-57.

12. Watanabe A, Omata T, Kinouchi H: Rapid reduction of acute subdural hematoma and redistribution of hematoma: a case report. Neurol Med Chir (Tokyo) 2010, 50(10):924-927.

doi:10.1186/1752-1947-7-67

Cite this article as: Park et al: Rapid resolution of acute subdural hematoma in child with severe head injury: a case report. Journal of Medical Case Reports 2013 7:67.

\section{Submit your next manuscript to BioMed Central and take full advantage of:}

- Convenient online submission

- Thorough peer review

- No space constraints or color figure charges

- Immediate publication on acceptance

- Inclusion in PubMed, CAS, Scopus and Google Scholar

- Research which is freely available for redistribution 